\title{
Predictors of ventriculostomy infection in a large single-center cohort
}

\author{
Ahmad Sweid, MD, ${ }^{1}$ Joshua H. Weinberg, BS, ${ }^{1}$ Rawad Abbas, BS, ${ }^{2}$ Kareem El Naamani, BS, ${ }^{3}$ \\ Stavropoula Tjoumakaris, MD, ${ }^{1}$ Christine Wamsley, BA, ${ }^{1}$ Erica J. Mann, BA, ${ }^{1}$ \\ Christopher Neely, BS, ${ }^{1}$ Jeffery Head, BA, ${ }^{1}$ David Nauheim, BA, ${ }^{1}$ Julie Hauge, BS, ${ }^{4}$ \\ M. Reid Gooch, MD, ${ }^{1}$ Nabeel Herial, MD, ${ }^{1}$ Hekmat Zarzour, MD, ${ }^{1}$ Tyler D. Alexander, MS, ${ }^{1}$ \\ Symeon Missios, MD, ${ }^{1}$ David Hasan, MD, ${ }^{5}$ Nohra Chalouhi, MD, ${ }^{1}$ James Harrop, MD, ${ }^{1}$ \\ Robert H. Rosenwasser, MD, ${ }^{1}$ and Pascal Jabbour, MD1
}

1Department of Neurosurgery, Thomas Jefferson University and Jefferson Hospital for Neuroscience, Philadelphia, Pennsylvania; ${ }^{2}$ American University of Beirut Faculty of Medicine, Beirut, Lebanon; ${ }^{3}$ Gilbert and Rose-Marie Chagoury School of Medicine, Beirut, Lebanon; ${ }^{4}$ University of Pennsylvania, Philadelphia, Pennsylvania; and ${ }^{5}$ Department of Neurosurgery, University of lowa, lowa City, lowa

OBJECTIVE External ventricular drain (EVD) placement is a common neurosurgical procedure. While this procedure is simple and effective, infection is a major limiting factor. Factors predictive of infection reported in the literature are not conclusive. The aim of this retrospective, single-center large series was to assess the rate and independent predictors of ventriculostomy-associated infection (VAI).

METHODS The authors performed a retrospective chart review of consecutive patients who underwent EVD placement between January 2012 and January 2018.

RESULTS A total of 389 patients were included in the study. The infection rate was $3.1 \%(n=12)$. Variables that were significantly associated with VAI were EVD replacement (OR 10, $p=0.001)$, bilateral EVDs $(O R$ 9.2, $p=0.009)$, duration of EVD placement (OR 1.1, $p=0.011)$, increased CSF output/day (OR 1.0, $p=0.001)$, CSF leak (OR 12.9, $p=0.001)$, and increased length of hospital stay (OR 1.1, $p=0.002)$. Using multivariate logistic regression, independent predictors of VAl were female sex (OR 7.1, 95\% Cl 1.1-47.4; $p=0.043)$, EVD replacement (OR 8.5, 95\% Cl 1.44-50.72; $p=0.027$ ), increased CSF output/day (OR 1.01, 95\% Cl 1.0-1.02; $p=0.023$ ), and CSF leak (OR 15.1, 95\% Cl 2.6-87.1; $p=0.003$ ).

CONCLUSIONS The rate of VAI was 3.1\%. Routine CSF collection (every other day or every 3 days) and CSF collection when needed were not associated with VAI. The authors recommend CSF collection when clinically needed rather than routinely.

https://thejns.org/doi/abs/10.3171/2020.2.JNS192051

KEYWORDS ventriculostomy-associated infection; external drainage; predictors of infection; hydrocephalus

$\mathrm{T}$ HE first historically documented ventriculostomy by Wernicke was performed in $1744 . .^{1}$ After more than 2 centuries, ventriculostomy remains an essential procedure in neurosurgery practice, with an estimated 20,000 external ventricular drains (EVDs) inserted annually. ${ }^{2}$ It is a crucial, lifesaving, simple procedure that can be performed at the bedside or in the operating room. EVD placement has a wide array of indications, including acute hydrocephalus, intracranial pressure (ICP) monitoring, posterior fossa surgeries, and administration of intraventricular antibiotics. ${ }^{3}$ Although it is a simple procedure, it carries serious complications that can markedly aggravate neurological outcome, morbidity, mortality, and hospital stay. ${ }^{4}$ Infection control remains a significant concern, with current reported infection rates varying from $0 \%$ to $45 \%$ across studies. ${ }^{5,6}$ Disparities have been attrib-

ABBREVIATIONS AIC = antibiotic-impregnated catheter; EVD = external ventricular drain; ICP $=$ intracranial pressure; NICU = neurology intensive care unit; VAI = ventriculostomy-associated infection.

SUBMITTED July 28, 2019. ACCEPTED February 7, 2020.

INCLUDE WHEN CITING Published online April 10, 2020; DOI: 10.3171/2020.2.JNS192051. 
uted to marked methodological differences, variability in definitions of infection, and sporadic use of antibiotics that often suppress detection of infection. Unfortunately, although numerous techniques, medications, and protocols have been used to reduce ventriculostomy-associated infection (VAI), the risk of VAI has been persistent; according to a retrospective review of 38,163 subjects, 7.3 per 100 patients experienced VAI ${ }^{7}$ On the other hand, we previously reported that the use of impregnated catheters supplemented by a standardized, evidence-based protocol for placement and maintenance of ventriculostomies reduced the rate of EVD infection from $6.7 \%$ to $0.9 \% .^{8}$ To reduce the infection rate, the Neurocritical Care Society published recommendations for standardizing the care and achieving evidence-based practice in 2016. ${ }^{9}$ The primary aim of this study was to identify the predictors and incidence of VAI in a large sample.

\section{Methods}

\section{Patient Population}

Consecutive patients who underwent placement of an EVD between January 2012 and December 2018 were enrolled in our study. A retrospective chart review for baseline characteristics, indication for EVD placement, treatment characteristics, and development of VAI was performed. The institutional review board approved the study design, and consent was waived due to the retrospective nature of the study. A database of all patients who had a ventriculostomy procedure was maintained for quality purposes.

\section{Definitions and Exclusion Criteria}

VAI was defined as fever $\left(38^{\circ} \mathrm{C}\right.$ for 30 minutes or $38.3^{\circ} \mathrm{C}$ ) at least 24 hours after EVD placement associated with CSF leukocytosis $>10$ cells $/ \mathrm{mm}^{3}$ (500 red blood cells equivalent to 1 white blood cell), increased proteins ( $>50$ $\mathrm{mg} / \mathrm{dl})$, and decreased glucose $(<50 \%$ of serum glucose) with positive CSF culture. To differentiate colonization from infection, an infection was determined when the Gram stain of the original CSF sample that produced a finding was consistent with the organism cultured in addition to the aforementioned criteria. Treatment is empirically started after CSF collection, and based on the bacteriology results, antibiotics were tapered accordingly. Exclusion criteria were age younger than 1 year, a systemic infection prior to or during EVD placement, CNS infection before or during EVD insertion, death within 5 days of ventriculostomy insertion, EVD inserted at an outside hospital, prior CSF leak, and an open scalp laceration.

\section{EVD Insertion and Maintenance}

All EVD insertions were performed using standard sterile precautions in the operating room, angiography suite, emergency department, or neurology intensive care unit (NICU). All individuals received an antibiotic-impregnated catheter (AIC; Bactiseal ventricular catheter coated with $0.15 \%$ clindamycin and $0.054 \%$ rifampicin; Codman, Johnson \& Johnson Co.). The EVD was introduced at a location approximately $1 \mathrm{~cm}$ anterior to the coronal suture in the midpupillary line. All patients who underwent EVD placement in the operating room received antibiotic pro- phylaxis with intravenous cefazolin for 24 hours unless the patient had a penicillin allergy, in which case intravenous vancomycin was utilized. For procedures performed in locations other than the operating room, antibiotics were not routinely administered. The EVD was not replaced unless it became dislodged or obstructed. It was inspected daily by the neurosurgical team for evidence of CSF leak and infection at the insertion site. Sampling and analysis of CSF were performed using standard aseptic techniques according to two protocols in a chronological order either routinely (once every other day or once every 3 days) or more recently when clinically relevant. Such analysis included cell count with differential, glucose, protein, Gram stain, and culture. The CSF output was recorded per hour, and the burette was emptied when it was full. The collecting bag was emptied only when it was full. The closed system was never breached except during CSF sampling and delivery of intrathecal drugs and when the system was obstructed. In case of system obstruction, a trial of flushing was performed in a standard aseptic technique using normal saline to relieve the obstruction, and only when this failed was the catheter exchanged.

\section{Data Collection}

Inpatient progress notes, operative notes, outpatient notes, laboratory data, and radiological images were evaluated for each patient. Variables collected for EVDtreated patients were baseline demographics (age, sex, and race), diagnosis, indication, surgical procedure (time of insertion, location, and duration of surgery), duration of placement, location of EVD insertion (operating room, NICU, or emergency department), intrathecal drug delivery, timing of insertion (6:00-17:59 vs 18:00-5:59), EVD CSF output/day (mean CSF output was calculated by adding the daily CSF output for the total duration divided by the number of days), presence of CSF leak, frequency of CSF sampling (number of CSF samples/infection-free total EVD placement duration), EVD replacement, other surgical or interventional procedures, length of hospital stay, steroid intake, and causative organism. CSF output was recorded per hour and per 12 hours by the care team. The average CSF output/day over the entire EVD duration was collected. A CSF leak was documented by the neurosurgical team in the medical charts and was considered present if the team observed CSF leaking from the wound or around the catheter. As mentioned above, the ventricular catheter was only replaced if it became dislodged or was obstructed. The replacement catheter was placed at the same location to avoid a new incision. In patients who developed a VAI, CSF output and CSF sampling were collected only during the infection-free period. Also, the frequency of CSF sampling for VAI patients was calculated according to the infection-free period the EVD was maintained, rather than the total EVD duration.

\section{Statistical Analysis}

Data were analyzed using statistical software (Stata SE 14.2, StataCorp). All patients were included in both the univariate analysis and multivariable regression analysis. Univariate analysis of discrete data, including a compari- 


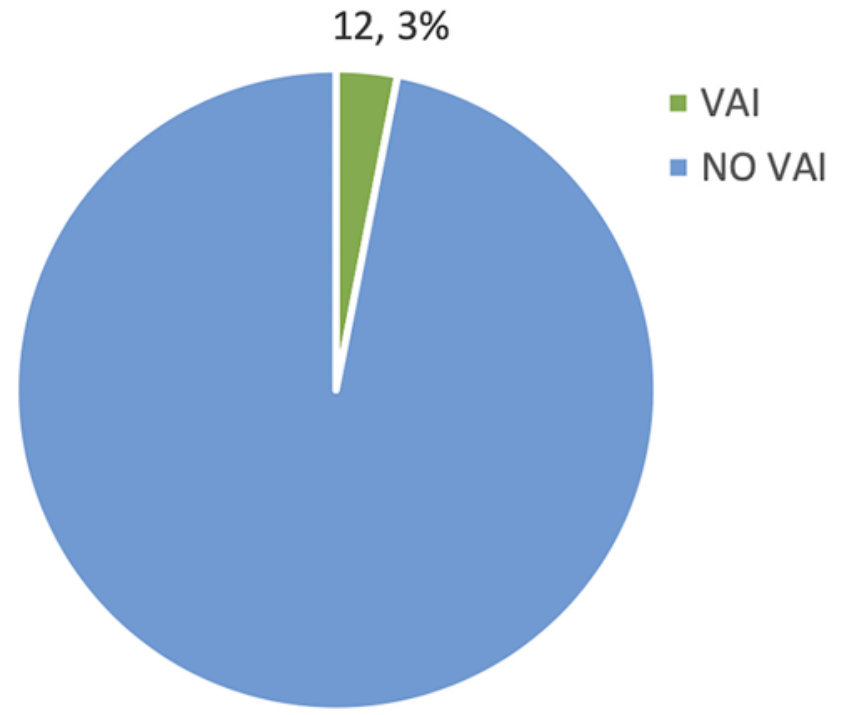

$377,97 \%$

FIG. 1. Pie chart showing the incidence of VAI. Figure is available in color online only.

son of secondary outcomes of infection rate, was performed using relevant chi-square analyses. Parametric dependent variables were analyzed using t-tests. Predictors of primary outcome of infection were evaluated through multivariable logistic regression analyses. Relevant variables were included in the model as predictors of VAI and as potential confounders. Odds ratios and $95 \%$ CIs were used to measure the strength of associations. All hypotheses were tested at an alpha $=0.05$ level of significance.

\section{Results}

Of 767 patients who underwent ventriculostomy placement between 2012 and 2018, 389 patients were included in the analysis; 378 patients were excluded from the study population because of death within 5 days of ventriculostomy insertion, the presence of prior CNS infection or systemic infection, or EVD insertion at an outside hospital. The VAI rate was $3.1 \%(\mathrm{n}=12)$ (Fig. 1). There were 7 cases $(58.3 \%)$ of gram-negative species, $4(33.3 \%)$ of gram-positive species, and 1 (8.3\%) of Candida species (Table 1 and Fig. 2).

\section{Baseline Characteristics}

A comparative analysis was performed between the infection group (those who developed a VAI) and the control group. There was no significant difference in mean age between the groups $(51.1 \pm 16.3$ [95\% CI 40.7-61.5] vs $56.7 \pm 15.6$ [95\% CI 55.1-58.3] years, $p=0.163$ ). The following variables were not significantly different between the groups: sex (female sex: 9 [75\%] vs 206 [54.6\%], p $=0.163)$, diabetes mellitus $(2[16.6 \%]$ vs $73[19.3 \%], \mathrm{p}=$ $0.816)$, procedural intervention (10 [83.3\%] vs 323 [85.7\%], $\mathrm{p}=0.820$ ), and steroid intake (3 [25.0\%] vs 107 [28.4\%], $\mathrm{p}=0.798$ ). The length of hospital stay was significantly
TABLE 1. Microbiological flora in the 12 VAls

\begin{tabular}{lc}
\hline Causative Organism & No. of Encounters \\
\hline Enterococcus sp. & 4 \\
\hline Yersiniaceae & 1 \\
\hline Pseudomonas sp. & 1 \\
\hline Enterobacteriaceae & 2 \\
\hline Staphylococcus sp. & 2 \\
\hline Streptococcus sp. & 1 \\
\hline Bacillus sp. & 1 \\
\hline Candida sp. & 1 \\
\hline
\end{tabular}

longer in the infection group by a mean of 10 days (27.6 \pm 17.6 [95\% CI $16.4-38.7$ ] vs $17.4 \pm 9.4$ [95\% CI 16.5-18.4] days, $\mathrm{p}=0.001)($ Table 2$)$.

\section{EVD-Related Variables}

A comparative analysis was performed between the infection group and control group. EVD replacement was observed in a significantly higher proportion in the infection group (5 [41.6\%] vs 25 [6.6\%], $\mathrm{p}=0.001)$. Similarly, having bilateral EVDs was observed at a significantly higher proportion in the infection group (2 [16.7\%] vs 8 [2.1\%], $\mathrm{p}=0.002)$. Duration of EVD placement was significantly longer in the infection group by a mean of 5 days $(15.5 \pm 6.0$ [95\% CI 11.9-19.8] days vs $10.3 \pm 6.0$ [95\% CI 9.7-10.9] days, $\mathrm{p}=0.008)$. CSF leak (4 [33.3\%] vs 14 [3.7\%], $\mathrm{p}=0.001)$ and mean CSF output/day (168.6 \pm 101.7 [95\% CI $100.2-236.9] \mathrm{ml} /$ day vs $92.2 \pm 63.2[95 \%$ CI $85.7-98.6] \mathrm{ml} / \mathrm{day}, \mathrm{p}=0.001$ ) were both significantly higher in the infection group. Time of placement (daytime vs nighttime, $p=0.616$ ), location of placement (operating room vs NICU, $p=0.631$ ), elevated opening pressure $(\mathrm{p}=$ $0.267)$, mean ICP $\left(29.2 \pm 7.3\right.$ [95\% CI 21.6-36.8] $\mathrm{cm} \mathrm{H}_{2} \mathrm{O}$ vs $28.0 \pm 7.7$ [95\% CI 26.7-29.3] $\mathrm{cm} \mathrm{H}_{2} \mathrm{O}, \mathrm{p}=0.715$ ), mean number of CSF collections (3.5 \pm 3.4 [95\% CI 1.4-15.7] vs $4.7 \pm 3.6$ [95\% CI 4.4-5.14], $\mathrm{p}=0.267)$, EVD flushing $(\mathrm{p}=$

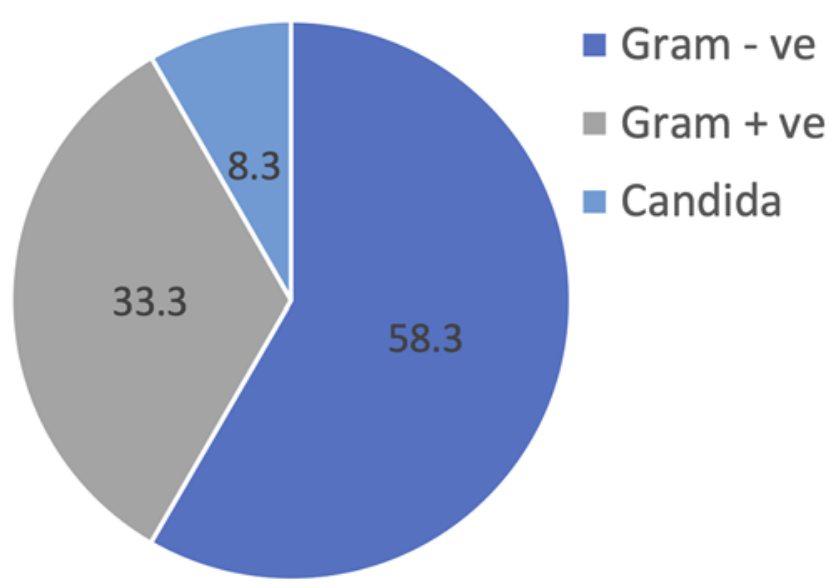

FIG. 2. Pie chart showing the breakdown of the causative microbiological organisms. + ve = positive; - ve $=$ negative. Figure is available in color online only. 
TABLE 2. Baseline characteristics of the two cohorts

\begin{tabular}{lccc}
\hline & Infection Group & Control Group & p Value \\
\hline No. of patients & $12(3.1)$ & $377(96.9)$ & \\
\hline Age, yrs & & & 0.120 \\
Mean \pm SD & $51.1 \pm 16.3$ & $56.7 \pm 15.6$ & \\
$95 \%$ Cl & $40.7-61.5$ & $55.1-58.3$ & 0.163 \\
\hline Sex & & & \\
Male & $3(25.0)$ & $171(45.4)$ & 0.520 \\
Female & $9(75.0)$ & $206(54.6)$ & \\
Indication for EVD & & & \\
SAH & $5(41.7)$ & $132(35.0)$ & \\
ICH & $4(33.3)$ & $83(22.0)$ & 0.249 \\
Tumor & $0(0.0)$ & $45(16.2)$ & 0.816 \\
Hydrocephalus & $1(8.3)$ & $34(9.0)$ & 0.820 \\
Other & $2(16.7)$ & $249(66.0)$ & 0.798 \\
\hline Hypertension & $6(50.0)$ & $73(19.4)$ & $0.001^{*}$ \\
\hline Diabetes mellitus & $2(16.7)$ & $323(85.7)$ & \\
\hline Procedural intervention & $10(83.3)$ & $107(28.4)$ & \\
\hline Steroid intake & $3(25.0)$ & $17.4 \pm 9.4$ & \\
\hline Length of stay, days & & $16.5-18.4$ & \\
Mean \pm SD & $27.6 \pm 17.6$ & & \\
95\% Cl & $16.4-38.7$ & & \\
\hline
\end{tabular}

$\mathrm{ICH}=$ intracerebral hemorrhage; $\mathrm{SAH}=$ subarachnoid hemorrhage.

Values are presented as the number (\%) unless indicated otherwise.

* Statistically significant.

0.413), and CSF sampling frequency (every 3 days, every other day, or when needed; $\mathrm{p}=0.845$ ) were not significantly different between the groups (Table 3 and Fig. 3).

The mean duration for onset of fever was $8 \pm 4.3$ days in the infection group. There was no significant difference in terms of onset of fever between gram-negative and gram-positive organisms ( 9.1 vs 7.5 days, $\mathrm{p}=0.50$ ).

\section{Univariate Logistic Regression}

In univariate analysis, the variables associated with infection were EVD replacement (OR 10, $\mathrm{p}=0.001)$, bilateral EVDs (OR 9.2, $\mathrm{p}=0.009)$, duration of EVD placement (OR 1.1, $\mathrm{p}=0.011)$, increased CSF output/day (OR 1.0, $\mathrm{p}$ $=0.001)$, CSF leak (OR 12.9, $\mathrm{p}=0.001)$, and increased length of hospital stay (OR 1.1, $\mathrm{p}=0.002)$.

The number of CSF collections and frequency of CSF sampling (every 3 days, once every other day, or when needed) did not show an association with infection. Similarly, diabetes mellitus, steroid intake, indication for EVD placement, location of placement (operating room or NICU), timing of EVD placement, and increased ICP were not associated with infection (Table 4).

\section{Multivariable Logistic Regression}

After controlling for variables, female sex (OR 7.1,95\% CI 1.1-47.4; $\mathrm{p}=0.043$ ), EVD replacement (OR 8.5, 95\% CI 1.44-50.72; $\mathrm{p}=0.027)$, increased CSF output/day (OR $1.01,95 \%$ CI $1.0-1.02 ; \mathrm{p}=0.023$ ), and CSF leak (OR 15.1, $95 \%$ CI $2.6-87.1 ; \mathrm{p}=0.003$ ) were found to be statistically significant.

Bilateral EVDs, duration of EVD placement, and length of hospital stay lost significance after controlling for other variables (Table 4 and Fig. 4).

\section{Discussion}

The ventriculostomy procedure is a lifesaving procedure. It is simple to perform and does not require complex settings. The main limitation of a ventriculostomy procedure is the risk of infection, as the catheter is a foreign body connecting the closed CSF space to the outside world. Therefore, insertion requires careful infection control regimens. It has been estimated that more than 20,000 EVDs were placed in the US in $2008 .{ }^{2}$ We have previously reported that a simple EVD infection protocol and the use of an AIC led to a decrease in the infection rate dramatically in a high-load tertiary center. ${ }^{8}$ A retrospective study performed by Murphy et al. concluded that VAI was an independent predictor of in-hospital mortality (41.2\% vs $36.5 \%$ ), composite unfavorable discharge outcomes (50\% vs $35 \%$ ), twice-longer length of stay than for non-VAI patients, and higher resource utilization measures..$^{10} \mathrm{~A}$ mortality rate of $15.1 \%-50 \%$ following infection has been reported. ${ }^{11,12}$ Our aim herein was to identify the incidence and independent factors predictive of ventriculostomy infection.

The incidence of VAI was 3.1\%. Data analysis identified variables that are associated with infection on univariate analysis, including bilateral EVDs (OR 9.2), duration of EVD placement (OR 1.1), and length of hospital stay (OR 1.1). Independent predictors of VAI were female sex (OR 7.1), EVD replacement (OR 8.5), increased CSF output/day (OR 1.01), and CSF leak (OR 15.1). When CSF 
TABLE 3. EVD management and maintenance variables of the two cohorts

\begin{tabular}{|c|c|c|c|}
\hline & Infection Group & Control Group & $\mathrm{p}$ Value \\
\hline No. of patients & $12(3.1)$ & $377(96.9)$ & \\
\hline EVD replacement & $5(41.6)$ & $25(6.6)$ & $0.001^{*}$ \\
\hline Bilateral EVDs & $2(16.7)$ & $8(2.1)$ & $0.002^{*}$ \\
\hline $\begin{array}{l}\text { Placement } \\
\text { Daytime } \\
\text { Nighttime }\end{array}$ & $\begin{array}{l}6(50.0) \\
6(50)\end{array}$ & $\begin{array}{l}186(49.3) \\
191(50.7)\end{array}$ & 0.616 \\
\hline $\begin{array}{l}\text { Location of placement } † \\
\text { Operating room } \\
\text { NICU }\end{array}$ & $\begin{array}{l}3(25.0) \\
9(75.0)\end{array}$ & $\begin{array}{r}72(19.4) \\
299(80.6)\end{array}$ & 0.631 \\
\hline Elevated ICP $\left(>20 \mathrm{~cm} \mathrm{H}_{2} \mathrm{O}\right)$ & $6(50.0)$ & $129(34.5)$ & 0.267 \\
\hline $\begin{array}{l}\mathrm{ICP}, \mathrm{cm} \mathrm{H}_{2} \mathrm{O} \\
\quad \text { Mean } \pm \mathrm{SD} \\
95 \% \mathrm{Cl}\end{array}$ & $\begin{array}{c}29.2 \pm 7.3 \\
21.6-36.8\end{array}$ & $\begin{array}{c}28.0 \pm 7.7 \\
26.7-29.3\end{array}$ & 0.715 \\
\hline $\begin{array}{l}\text { No. of CSF collections } \\
\text { Mean } \pm \text { SD } \\
95 \% \mathrm{Cl}\end{array}$ & $\begin{array}{r}3.5 \pm 3.4 \\
1.4-15.7\end{array}$ & $\begin{array}{l}4.7 \pm 3.6 \\
4.4-5.14\end{array}$ & 0.267 \\
\hline $\begin{array}{l}\text { EVD duration, days } \\
\text { Mean } \pm \text { SD } \\
\quad 95 \% \mathrm{Cl}\end{array}$ & $\begin{array}{r}15.5 \pm 6.0 \\
11.9-19.8\end{array}$ & $\begin{array}{r}10.3 \pm 6.0 \\
9.7-10.9\end{array}$ & $0.008^{*}$ \\
\hline $\begin{array}{l}\text { CSF sampling frequency } \\
\text { When needed } \\
\text { Every } 3 \text { days } \\
\text { Every other day }\end{array}$ & $\begin{array}{l}2(16.7) \\
3(25.0) \\
7(58.3)\end{array}$ & $\begin{array}{r}58(15.4) \\
71(18.9) \\
248(65.7) \\
\end{array}$ & 0.845 \\
\hline Flushing & $0(0)$ & $20(5.3)$ & 0.413 \\
\hline CSF leak & $4(33.3)$ & $14(3.7)$ & $0.001^{*}$ \\
\hline $\begin{array}{l}\text { CSF output/day, ml } \\
\text { Mean } \pm \text { SD } \\
95 \% \mathrm{Cl}\end{array}$ & $\begin{array}{c}168.6 \pm 101.7 \\
100.2-236.9\end{array}$ & $\begin{array}{c}92.2 \pm 63.2 \\
85.7-98.6\end{array}$ & $0.001^{*}$ \\
\hline
\end{tabular}

* Statistically significant.

† Data are missing for 6 patients in the control group.

collection was converted from a continuous variable into a ratio (frequency; number of CSF collections/infectionfree total EVD placement duration) categorized into once every 3 days, once every other day, and when needed,
TABLE 4. Univariate and multivariate predictors of ventriculostomy infection

\begin{tabular}{lrrrrrrr}
\hline & \multicolumn{2}{c}{ Univariate } & & \multicolumn{3}{c}{ Multivariate } \\
\cline { 2 - 3 } \cline { 6 - 7 } & OR & $p$ Value & & OR & p Value & $95 \% \mathrm{Cl}$ \\
\hline Female sex & 1.2 & 0.176 & & 7.1 & $0.043^{*}$ & $1.1-47.4$ \\
\hline EVD replacement & 10.0 & $0.001^{*}$ & & 8.5 & $0.027^{*}$ & $1.44-50.72$ \\
\hline Bilateral EVDs & 9.2 & $0.009^{*}$ & & & \\
\hline $\begin{array}{l}\text { Duration of EVD } \\
\text { placement }\end{array}$ & 1.1 & $0.011^{*}$ & & & \\
\hline CSF output/day & 1.0 & $0.001^{*}$ & 1.01 & $0.023^{*}$ & $1.0-1.02$ \\
\hline CSF leak & 12.9 & $0.001^{*}$ & 15.1 & $0.003^{*}$ & $2.6-87.1$ \\
\hline Length of hospital stay & 1.1 & $0.002^{*}$ & & & \\
\hline
\end{tabular}

* Statistically significant.

analysis showed that there was no significant difference among the 3 groups in terms of VAI incidence. The rate of ventriculostomy infection reported in the literature ranges between $0 \%$ and $25.8 \%$, even reaching $45 \%$ in one study. ${ }^{7,9}$ 11,13-19 This wide range is due to the variable definitions of positive CSF infection. Lewis et al. identified 17 different definitions ${ }^{20}$ In a previous publication, we reported a drop of VAI rate from $6.7 \%$ to $0.9 \%$ by implementing an evidence-based protocol for EVD placement and maintenance and the use of AICs. ${ }^{8}$ Although the infection rate in this study is higher than what we previously reported $(0.9 \%), 3.1 \%$ is still acceptable and lies in the lower range of what is reported in the literature.

Major risk factors for infection fall into one of 2 broad categories: those that promote bacterial growth and those that promote bacterial access to the CSF. ${ }^{14}$ In our study, one factor that fell under the category of bacterial growth was our patient sample; the indication for ventriculostomy placement in $45 \%$ of cases was for subarachnoid hemorrhage and intracerebral hemorrhage, and those patients are often bedridden and immunocompromised. Factors that fell under the category of bacterial access, seen in a greater proportion in the infection group, were EVD replacement, bilateral EVDs, longer EVD duration, and CSF leak.

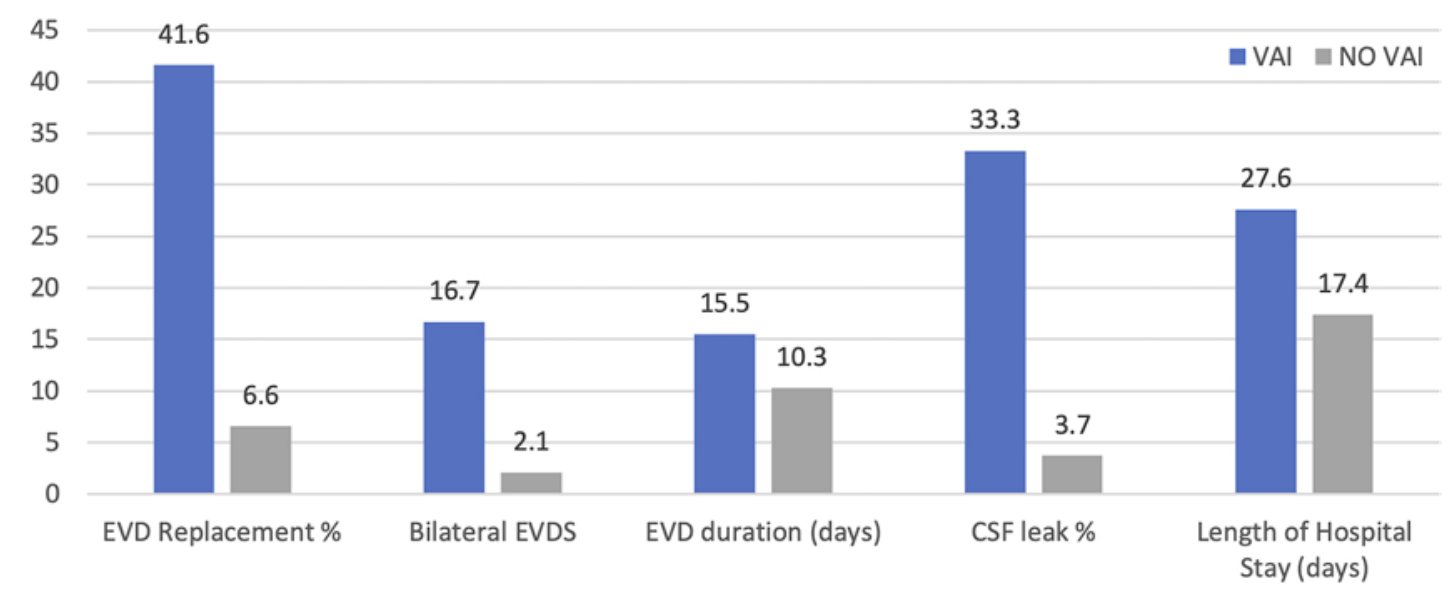

FIG. 3. Bar graph showing variables significantly associated with VAI. Figure is available in color online only. 


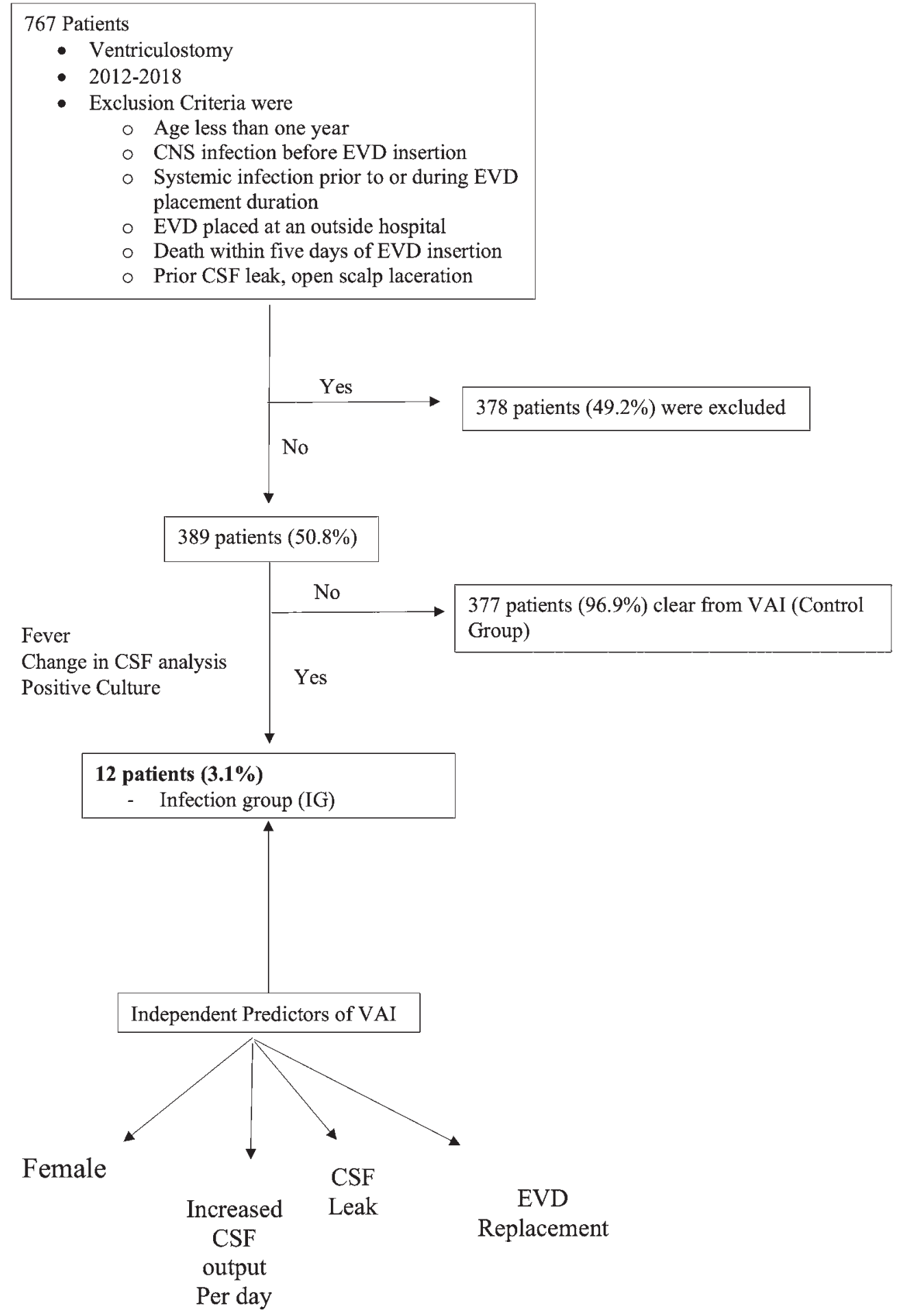

FIG. 4. Flowchart for study design and outcomes.

Patients admitted to the hospital usually do not undergo prophylactic workup such as urine analysis, urine culture, or blood culture if they have a Foley catheter or an arterial line. However, this is not the practice with EVDs. At our institution, and in others, routine CSF collection either every other day or once every 3 days is performed.
Recently, there has been a change in the protocol where CSF collection is performed only when needed. The main disadvantages of routine CSF sampling are system breach, additional CSF studies with any biochemical CSF variations, and cost. The frequency of CSF collection, whether routine CSF collection (every other day or every 3 days) 
or when needed, was not associated with additional risk of infection. Such outcomes are supported by previously published data; however, we add to the current literature that CSF collection when needed does not increase the risk of infection. Kitchen et al., Ramanan et al., and Arabi et al. reported that CSF sampling does not increase the risk of CNS infection. ${ }^{6,21,22}$ On the other hand, Hoefnagel et al. reported that CSF sampling frequency was a risk factor for infection. ${ }^{23}$ Furthermore, the CLEAR III (Clot Lysis Evaluating Accelerated Resolution of Intraventricular Hemorrhage Phase III) trial reported that frequent instrumentation of the closed CSF drainage system might increase infection rates. ${ }^{24}$ Based on our expertise, the current outcomes mentioned above, previously published data, and the disadvantages of routine CSF sampling, we changed our practice to perform CSF collection when clinically deemed necessary.

In our protocol, catheter replacement is only performed in cases of system obstruction after a failed attempt to relieve the obstruction by flushing or inadvertent dislodgment. EVD replacement was an independent predictor of VAI with a 10-fold increased risk. Several societies have refuted the dilemma of exchanging the ventricular catheter in a fixed interval to break the cycle of long EVD placement to prevent infection. In addition, EVD duration lost significance in multivariate analysis, which may be due to AICs. Recently, the Infectious Diseases Society of America recommended against a fixed interval exchange of ventricular catheters. ${ }^{3}$ Chi et al. reported in their study that there is an increased risk of infection with each subsequent catheter inserted. ${ }^{25}$ The alternative sites for EVD insertion are limited due to their proximity to eloquent areas. The left side is the dominant hemisphere, and posterior to the coronal suture is the motor strip. The catheter should be fixed well to prevent any dislodgment as the risk of infection increases by 10 times. The contralateral side may be an alternative over reinsertion at the same site with careful risk assessment. Conclusions in the literature regarding duration that the EVD is in place and infection are controversial. ${ }^{14,26,27}$ One of the postulates for CSF infection is through retrograde contamination of bacteria from the skin that migrate along the catheter track. Multiple adjustments may be performed to limit this retrograde migration, including increasing the length of the tunneling, ${ }^{28-30}$ using antibiotic-coated catheters, ${ }^{8}$ maintaining hygienic care, and weaning the ventriculostomy when clinically relevant. ${ }^{31}$ It has been reported that patients with an EVD in place for more than 15 days have a 7 times increased risk of developing infection compared with patients with an EVD duration of less than 15 days. ${ }^{32}$

CSF leak results in CSF contamination through direct contact with skin microbiological flora. In our series, CSF leak increased the risk of infection by 15 -fold. Schade et al. performed a retrospective analysis comparing ventricular drainage with lumbar drainage. ${ }^{32}$ They concluded that the bacterial meningitis risk was higher in ventricular drainage (15\%) than in lumbar drainage (7\%) and reported that CSF leak was an independent predictor of infection. They used a simple EVD without systemic antibiotics and reported that $82 \%$ of the microbiological findings were gram-positive organisms.
In this study, the use of AICs resulted in a preferential selection of the causative microorganism, gram-negative bacteria, which has been reported in the literature..$^{17,33}$ The causative organisms of infection in our study were gramnegative bacteria in $58.3 \%$ of cases, followed by grampositive bacteria in $33.3 \%$. These results fall in line with a previous report published from our institution, stating that the implementation of AICs had led to a decline in the gram-positive infections. ${ }^{8}$ Previous data from 23 major studies reported that the majority of ventriculostomy infections are caused by gram-positive cocci, although gram-negative and Candida species were still isolated..$^{14}$

The main limitation of this study is its retrospective nature. The reviewed charts extend over 9 years, and earlier charts were documented at a time when electronic medical records were not as developed as they are now. Also, although a standardized protocol is designed for EVD management, some physicians may defer from the protocol.

\section{Conclusions}

In our study, the rate of VAI was $3.1 \%$. The implementation of a standardized protocol, meticulous hygienic care, and AICs are measures to maintain the infection rate in the lower range. VAI is a serious complication that results in increased morbidity, length of stay, and cost. Female sex, EVD replacement, increased CSF output/day, and CSF leak were independent predictors of VAI. Routine CSF collection (every other day or every 3 days) and CSF collection when needed were not associated and do not increase the risk of infection. We recommend CSF collection when clinically needed rather than routinely due to the aforementioned reasons.

\section{References}

1. Aschoff A, Kremer P, Hashemi B, Kunze S. The scientific history of hydrocephalus and its treatment. Neurosurg Rev. 1999;22(2-3):67-95.

2. O’Neill BR, Velez DA, Braxton EE, et al. A survey of ventriculostomy and intracranial pressure monitor placement practices. Surg Neurol. 2008;70(3):268-273.

3. Tunkel AR, Hasbun R, Bhimraj A, et al. 2017 Infectious Diseases Society of America's clinical practice guidelines for healthcare-associated ventriculitis and meningitis. Clin Infect Dis. 2017;64(6):e34-e65.

4. Beer R, Lackner P, Pfausler B, Schmutzhard E. Nosocomial ventriculitis and meningitis in neurocritical care patients. $J$ Neurol. 2008;255(11):1617-1624.

5. Engelhard HH, Andrews CO, Slavin KV, Charbel FT. Current management of intraventricular hemorrhage. Surg Neurol. 2003;60(1):15-22.

6. Kitchen WJ, Singh N, Hulme S, et al. External ventricular drain infection: improved technique can reduce infection rates. Br J Neurosurg. 2011;25(5):632-635.

7. Poblete R, Zheng L, Raghavan R, et al. Trends in ventriculostomy-associated infections and mortality in aneurysmal subarachnoid hemorrhage: data from the Nationwide Inpatient Sample. World Neurosurg. 2017;99:599-604.

8. Harrop JS, Sharan AD, Ratliff J, et al. Impact of a standardized protocol and antibiotic-impregnated catheters on ventriculostomy infection rates in cerebrovascular patients. Neurosurgery. 2010;67(1):187-191.

9. Fried HI, Nathan BR, Rowe AS, et al. The insertion and management of external ventricular drains: an evidence-based 
consensus statement: a statement for healthcare professionals from the Neurocritical Care Society. Neurocrit Care. 2016;24(1):61-81.

10. Murphy RK, Liu B, Srinath A, et al. No additional protection against ventriculitis with prolonged systemic antibiotic prophylaxis for patients treated with antibiotic-coated external ventricular drains. J Neurosurg. 2015;122(5):1120-1126.

11. Bari ME, Haider G, Malik K, et al. Outcomes of post-neurosurgical ventriculostomy-associated infections. Surg Neurol Int. 2017;8:124.

12. Fabiano AJ, Gruber TJ, Baxter MS. Increased ventriculostomy infection rate with use of intraventricular tissue plasminogen activator: a single-center observation. Clin Neurol Neurosurg. 2013;115(11):2362-2364.

13. Camacho EF, Boszczowski I, Freire MP, et al. Impact of an educational intervention implanted in a neurological intensive care unit on rates of infection related to external ventricular drains. PLoS One. 2013;8(2):e50708.

14. Lozier AP, Sciacca RR, Romagnoli MF, Connolly ES Jr. Ventriculostomy-related infections: a critical review of the literature. Neurosurgery. 2002;51(1):170-182.

15. Phan K, Schultz K, Huang C, et al. External ventricular drain infections at the Canberra Hospital: a retrospective study. $J$ Clin Neurosci. 2016;32:95-98.

16. Rappaport ZH, Shalit MN. Perioperative external ventricular drainage in obstructive hydrocephalus secondary to infratentorial brain tumours. Acta Neurochir (Wien). 1989;96(34):118-121.

17. Talibi S, Tarnaris A, Shaw SA. Has the introduction of antibiotic-impregnated external ventricular drain catheters changed the nature of the microorganisms cultured in patients with drain-related infection? A single neurosurgical centre's experience. Br J Neurosurg. 2016;30(5):560-566.

18. Taylor WA, Todd NV, Leighton SE. CSF drainage in patients with posterior fossa tumours. Acta Neurochir (Wien). 1992;117(1-2):1-6.

19. Zabramski JM, Whiting D, Darouiche RO, et al. Efficacy of antimicrobial-impregnated external ventricular drain catheters: a prospective, randomized, controlled trial. J Neurosurg. 2003:98(4):725-730.

20. Lewis A, Wahlster S, Karinja S, et al. Ventriculostomyrelated infections: the performance of different definitions for diagnosing infection. Br J Neurosurg. 2016;30(1):49-56.

21. Arabi Y, Memish ZA, Balkhy HH, et al. Ventriculostomyassociated infections: incidence and risk factors. Am J Infect Control. 2005;33(3):137-143.

22. Ramanan M, Lipman J, Shorr A, Shankar A. A meta-analysis of ventriculostomy-associated cerebrospinal fluid infections. BMC Infect Dis. 2015;15:3.

23. Hoefnagel D, Dammers R, Ter Laak-Poort MP, Avezaat CJ. Risk factors for infections related to external ventricular drainage. Acta Neurochir (Wien). 2008;150(3):209-214.

24. Dey M, Stadnik A, Riad F, et al. Bleeding and infection with external ventricular drainage: a systematic review in comparison with adjudicated adverse events in the ongoing Clot Lysis Evaluating Accelerated Resolution of Intraventricular Hemorrhage Phase III (CLEAR-III IHV) trial. Neurosurgery. 2015;76(3):291-301.
25. Chi H, Chang K-Y, Chang H-C, et al. Infections associated with indwelling ventriculostomy catheters in a teaching hospital. Int J Infect Dis. 2010;14(3):e216-e219.

26. Alleyne CH Jr, Hassan M, Zabramski JM. The efficacy and cost of prophylactic and perioprocedural antibiotics in patients with external ventricular drains. Neurosurgery. 2000;47(5):1124-1129.

27. Roitberg BZ, Khan N, Alp MS, et al. Bedside external ventricular drain placement for the treatment of acute hydrocephalus. Br J Neurosurg. 2001;15(4):324-327.

28. Khanna RK, Rosenblum ML, Rock JP, Malik GM. Prolonged external ventricular drainage with percutaneous long-tunnel ventriculostomies. J Neurosurg. 1995;83(5):791-794.

29. Long TD, Kallmes DF, Hanel R, et al. Novel aspiration catheter design for acute stroke thrombectomy. J Neurointerv Surg. 2019;11(2):190-195.

30. Omar MA, Mohd Haspani MS. The risk factors of external ventricular drainage-related infection at Hospital Kuala Lumpur: an observational study. Malays J Med Sci. 2010;17(3):48-54.

31. Park P, Garton HJ, Kocan MJ, Thompson BG. Risk of infection with prolonged ventricular catheterization. Neurosurgery. 2004;55(3):594-601.

32. Schade RP, Schinkel J, Visser LG, et al. Bacterial meningitis caused by the use of ventricular or lumbar cerebrospinal fluid catheters. J Neurosurg. 2005;102(2):229-234.

33. Atkinson RA, Fikrey L, Vail A, Patel HC. Silver-impregnated external-ventricular-drain-related cerebrospinal fluid infections: a meta-analysis. J Hosp Infect. 2016;92(3):263-272.

\section{Disclosures}

Dr. Jabbour is a consultant for Medtronic and MicroVention. Dr. Tjoumakaris is a consultant for Stryker.

\section{Author Contributions}

Conception and design: Jabbour, Sweid. Acquisition of data: Sweid, Weinberg, Abbas, El Naamani, Wamsley, Mann, Neely, Head, Nauheim, Hauge. Analysis and interpretation of data: Sweid, Weinberg, Abbas, El Naamani. Drafting the article: Head. Critically revising the article: Jabbour, Weinberg, Abbas, Tjoumakaris, Gooch, Herial, Zarzour, Hasan, Chalouhi, Harrop, Rosenwasser. Reviewed submitted version of manuscript: Sweid, Abbas, El Naamani. Approved the final version of the manuscript on behalf of all authors: Jabbour. Statistical analysis: Weinberg, Alexander, Missios. Study supervision: Jabbour.

\section{Supplemental Information}

\section{Previous Presentations}

The abstract of this paper was accepted as an e-poster at the 2019 American Association of Neurological Surgeons Annual Meeting, San Diego, California, April 13-17, 2019.

\section{Correspondence}

Pascal Jabbour: Thomas Jefferson University Hospital, Philadelphia,PA.pascal.jabbour@jefferson.edu. 